\title{
A PATHOBIOLOGICAL ROLE OF THE INSULIN RECEPTOR IN CHRONIC LYMPHOCYTIC LEUKEMIA
}

\author{
Kamlai Saiya-Cork, MS ${ }^{1}$, Roxane Collins, BS ${ }^{1}$, Brian Parkin, MD1', Peter Ouillette, MT \\ (ASCP) ${ }^{1}$, Erlene Kuizon, MD ${ }^{1}$, Lisa Kujawski, MD ${ }^{1}$, Harry Erba, MD, PhD ${ }^{1}$, Erica \\ Campagnaro, MD ${ }^{1}$, Kerby Shedden, PhD $^{2}$, Mark Kaminski, MD ${ }^{1}$, and Sami N. Malek, MD ${ }^{1,3}$ \\ ${ }^{1}$ Department of Internal Medicine, Division of Hematology and Oncology, University of Michigan, \\ Ann Arbor, MI, USA \\ 2 Department of Statistics, University of Michigan, Ann Arbor, MI, USA
}

\begin{abstract}
Purpose-The chromosomal deletion 11q affects biology and clinical outcome in CLL but del11q-deregulated genes remain incompletely characterized.
\end{abstract}

Experimental Design-We have employed integrated genomic profiling approaches upon CLL cases with and without del11q to identify 11q-relevant genes.

Results-We have identified differential expression of the insulin receptor (INSR) in CLL, including high-level INSR expression in the majority of CLL with del11q. High INSR mRNA expression in 11q CLL ( 10 -fold higher mean levels than other genomic categories) was confirmed by Q-PCR in 247 CLL cases. INSR protein measurements in 257 CLL cases through FACS, compared with measurements in normal CD19+ B-cells and monocytes, confirmed that a subset of CLL aberrantly expresses high INSR levels. INSR stimulation by insulin in CLL cells $e x$ vivo resulted in the activation of canonical INSR signaling pathways, including the AKT-mTOR and Ras/Raf/Erk pathways, and INSR activation partially abrogated spontaneous CLL cell apoptosis ex vivo. Higher INSR levels correlated with shorter time to first therapy (TTFT) and shorter overall survival (OS). In bivariate analysis, INSR expression predicted for rapid initial disease progression and shorter OS in ZAP-70 low/negative CLL. Finally, in multivariate analysis (ZAP-70 status, $\operatorname{IgV}_{\mathrm{H}}$ status and INSR expression), we detected elevated hazard ratios and trends for short OS for CLL cases with high INSR expression (analyzed inclusive or exclusive of cases with del11q).

Conclusions-Our aggregate biochemical and clinical outcome data suggest biologically meaningful elevated INSR expression in a substantial subset of all CLL cases, including many cases with del11q.

\footnotetext{
${ }^{3}$ To whom correspondence should be sent: Sami N. Malek, MD, Assistant Professor, Department of Internal Medicine, Division of Hematology and Oncology, University of Michigan, 1500 E. Medical Center Drive, Ann Arbor, MI 48109-0936., smalek@med.umich.edu. Phone: 734-763-2194. Fax: 734-647-9654.

Individual contributions: Kamlai Saiya-Cork, Peter Ouillette and Sami Malek performed the laboratory research. Roxane Collins, Brian Parkin, Erica Campagnaro, Harry Erba, Erlene Kuizon, Mark Kaminski, Lisa Kujawski and Sami Malek enrolled patients and contributed and analyzed clinical data. Kerby Shedden assisted with statistical analysis.

Sami Malek conceived the study.

Kamlai Saiya Cork, Peter Ouillette and Sami Malek wrote the paper.

Conflict of Interest: None of the authors have a conflict of interest.
} 


\section{Keywords}

CLL; Insulin receptor; apoptosis; deletion 11q; disease progression

\section{INTRODUCTION}

Chronic lymphocytic leukemia (CLL) is the most common form of adult leukemia in the

Western world, and is characterized by a highly variable clinical course(1). CLL is heterogeneous, and several disease-related factors have been identified that classify CLL into biologically distinct and clinically relevant subtypes. Lack of mutations in the immunoglobulin heavy-chain variable-region $\left(\operatorname{Ig} V_{H}\right)$ genes, increased expression of zetaassociated protein of $70 \mathrm{kDa}$ (ZAP-70), presence of del17p/p53 aberrations, del11q, and elevated genomic complexity are some of the molecular parameters which have been associated with an aggressive disease course, shortened disease-free intervals, or compromised survival (2-23). It is likely that additional factors will be identified that have an effect on CLL biology and clinical behavior, particularly in disease subsets.

Interstitial deletions on the long arm of chromosome 11 (del11q) occur in 15-20\% of all CLL and have been associated with relatively more progressive and aggressive CLL. Given that a comprehensive view of del11q-associated molecular deregulations has not yet emerged, and given the importance of del11q in CLL clinical outcome, studies into the mechanisms of del11q-associated phenotypes in CLL seemed warranted. One of the genes implicated in del11q-associated biology in CLL is ATM, which is mono-allelically deleted through all 11q deletions that are defined through the clinically used 11q FISH probe(2426). Mutations in $A T M$ have been identified on the retained allele in a minority subset of CLL with del11q, and CLL cases with del11q and mutated ATM have been proposed to have a more aggressive disease course than CLL cases with del11q and wildtype ATM (27,28). As it has been observed that $A T M$ mutations in the setting of del11q are acquired as part of CLL evolution, it is not likely that ATM-null states drive initial CLL disease progression. Thus the molecular drivers of CLL disease progression in general and in the setting of 11q deletions in particular remain incompletely understood. One such driver may be TCL1, which is often expressed at relatively high levels in CLL cells with del11q and has been proposed as a contributor to B-cell receptor responsiveness and CLL disease progression(29). Very little additional information is available about del11q-linked biology in CLL, and a molecular explanation as to why CLL cells would select for interstitial deletions on 11q (in the absence of prior therapy) has not been advanced.

In this study, we have used integrated genomic profiling approaches to identify stable transcriptome differences that exist between CLL with and without del11q. Array-based transcriptome analysis identified, for the first time, increased and preferential expression of the INSR in CLL with del11q, a finding that was validated in a large cohort of highly characterized CLL cases. INSR expression was found at varying absolute levels in CLL and at aberrantly high levels in $~ 15-20 \%$ of CLL cases. INSR stimulation by insulin activated canonical INSR signaling pathways and partially abrogated ex vivo CLL cell apoptosis. Importantly, through FACS-based INSR quantitation in a prospectively collected CLL cohort of $>250$ patients, we found that INSR expression correlated with progressive CLL across a wide range of absolute expression levels. This study constitutes the first description of a pathobiological role of the INSR in CLL and provides an impetus for further clinical studies of the relevance of high INSR expression in CLL subsets. 


\section{METHODS}

\section{Patients}

Between January 2005 and October 2009, 267 patients evaluated at the University of Michigan Comprehensive Cancer Center were enrolled onto this study. The trial was approved by the University of Michigan Institutional Review Board (IRBMED \#2004-0962) and written informed consent was obtained from all patients prior to enrollment. INSR data from 257 of these 267 patients were included in this analysis (5 patients enrolled on the study were excluded from analysis due to a diagnosis that was not CLL, and 5 patients had insufficient cryopreserved cells available).

Regardless of whether the subjects were originally diagnosed at our institution or another, we used the same CLL diagnostic criteria, based on the National Cancer Institute-Working Group Guidelines for CLL(30). Eligible patients needed to have an absolute lymphocytosis (greater than 5000 mature lymphocytes per $\mu \mathrm{l}$ ), and lymphocytes needed to express CD19, CD23, sIg (weak) and CD5 in the absence of other pan-T-cell markers.

Time to first therapy (TTFT) and overall survival (OS) were based on the CLL diagnosis date as previously defined(6). CLL treatment was defined as cytotoxic chemotherapy and/or monoclonal antibody therapy for CLL. Clinical information, including Rai stage; lymph node size and serial absolute lymphocyte count (ALC) measurements (at least 3) at the time of enrollment; and all treatments given was collected on all patients. Patient samples were characterized for selected CLL-associated chromosomal aberrations as a routine clinical test at the Mayo Clinic using FISH, as previously described(6).

\section{Cell Isolation}

Cell Purification-Peripheral blood mononuclear cells from CLL patients were isolated by Ficoll gradient centrifugation (GE Healthcare), aliquoted into FCS with 10\% DMSO, and cryopreserved in liquid nitrogen. For purification of CD19+ cells using negative selection, cryopreserved PBMCs derived from CLL patients were washed and recovered by centrifugation and then treated with anti-human CD3 (Miltenyi Biotec \#130-050-101) and anti-human CD14 microbeads (Miltenyi Biotec \#130-050-201) per manufacturer's recommendations. Cell suspensions were run through Miltenyi MACS LS separation columns (\#130-042-401) in order to negatively enrich for CD19+ B cells. This resulted in greater than $90 \%$ CD19+ cells. For mRNA isolation, CD19 single-positive cells were sorted on a high-speed FACSAria (Becton Dickinson) sorter as described(31).

\section{Preparation of CLL-derived Amplified RNA for Hybridization to Affymetrix Human 1332.0 Plus Arrays and Data Analysis}

Nineteen selected CLL samples (see Supplementary Table 1) were sorted to purity using a high-speed FACSAria (Becton Dickinson) sorter and RNA extracted using the Trizol reagent. RNA was further purified using the RNeasy kit (Qiagen). 50ng total RNA was amplified using the Ovation RNA Amplification system (NuGen, Inc.), labeled with the FLOvation cDNA Biotin module (NuGen, Inc.) and hybridized to the Human 1332.0 Plus GeneChip (Affymetrix) following the manufacturer's recommended protocols.

Affymetrix GeneChip data were analyzed as described (31). Raw probe-level data were converted to expression measures using the Robust Multi-array Average (RMA) method, which is implemented in the Affymetrix package of Bioconductor (32). Briefly, the raw perfect match (PM) probes are first quartile normalized to reduce array-to-array variation. The normalized probe data are then converted to an expression measure (log scale) for each gene on each chip. For differential expression analysis relating to 11q deletion status, we 
used two-sample Z-tests to compare the mean log-scale expression level between del11q and non-del11q samples. Genes with a False Discovery Rate (33) below 0.1 were selected, then fold-changes, FDR values, and Z-scores were used to identify genes having a strong association with $11 \mathrm{q}$ deletion status. There were 83 probe sets meeting this criterion. These probe sets are listed in Table 1, sorted by significance levels. Expression array data have been deposited with GEO (GEO \# pending).

\section{Measurement of Gene Expression using Q-PCR}

RNA was prepared from 2-4 $\times 10^{6}$ FACS-sorted CD19+ cells from all CLL cases using the Trizol reagent and resuspended in 50 $\mu \mathrm{l}$ DEPC-treated water. Twenty $\mu \mathrm{l}$ complementary DNA was made from $\sim 50 \mathrm{ng}$ of RNA using the Superscript III first strand synthesis kit (Invitrogen) and random priming. Primers and TaqMan-based probes were purchased from Applied Biosystems (Primers-on-demand). Primer/probe mixtures included: INSR (Hs00169631_m1) and GAPD (Hu GAPD). Duplicate amplification reactions included primers/probes, TaqMan ${ }^{\circledR} 2 \times$ Universal PCR Master Mix, No AmpErase UNG and $1 \mu$ of cDNA in a 20ul reaction volume. Reactions were done on an ABI 7900HT machine. Normalization of relative copy number estimates for INSR mRNA was done with the $\mathrm{Ct}$ values for GAPD as reference (Ct mean INSR - Ct mean GAPD). Comparisons between CLL subgroups were performed though subtractions of means of normalized $\mathrm{Ct}$ values.

\section{Immunoblotting and immunoprecipitation}

Antibodies used in this study were: anti-alpha tubulin (DM1A; Santa Cruz Biotech \#SC-32293), anti-IRS-1 (C-20; Santa Cruz Biotech \#SC-559), anti-insulin receptor beta (CT-3; Santa Cruz Biotech \#SC-57342), anti-ERK 1/2 (Cell Signaling \#9106), antiphospho-S6 ribosomal protein (Ser235/236; Cell Signaling \#2211S), anti-phospho-P44/42 MAPK (ERK 1/2) (Thr202/Tyr204; Cell Signaling \#9106S), anti-phospho p70 S6 kinase (Thr389; Cell Signaling \#9205S), anti-phospho AKT (Ser473; Cell Signaling \#9271 and \#4060), anti-AKT (Cell Signaling \#9272), anti-phosphotyrosine antibody 4G10 (Millipore \#05-1050), and anti-actin (AC-40; Sigma-Aldrich\# A3853).

Immunoblotting to measure INSR levels was performed on cell lysates from CD19+ cells obtained through negative selection from selected CLL cases. Cell pellets containing $10^{7}$ cells were lysed in $100 \mu \mathrm{l}$ of lysis buffer (1\% Triton X-100 [Sigma-Aldrich \#T8532], 50mM Tris pH 8.0 [Sigma-Aldrich \#T6066], 100mM NaCl [Sigma-Aldrich \#S7653], $20 \mathrm{mM} \mathrm{NaF}$ [Fisher Scientific \#S299], 2mM EDTA [Sigma-Aldrich \#ED2SS] and 2 mM EGTA [Sigma\# E3889] containing 1\% (v/v) protease inhibitor cocktail [Sigma-Aldrich \#P8340], phosphatase inhibitor cocktail [Sigma-Aldrich \#02850], PMSF [Thermo Fisher Scientific \#36978] and $1 \mathrm{mM}$ sodium orthovanadate [Alfa Aesar \#13721-39-6]). Lysates were cleared by centrifugation at $14,000 \mathrm{RPM}$ for 10 minutes at $4^{\circ} \mathrm{C}$ and supernatants brought to $1 \times$ SDS-PAGE sample buffer and boiled. Protein was fractionated on SDS-PAGE gels and transferred onto PVDF membrane, then blocked for $1 \mathrm{hr}$ in 5\% non-fat dry milk in Trisbuffered saline-Tween-20 (TBS-T). For anti-phosphotyrosine immunoblotting, blocking was done using 5\% BSA (Sigma-Aldrich \#A3059). Membranes were incubated in primary antibodies in milk/TBS-T, washed and finally incubated with appropriate HRP-conjugated secondary antibodies. The membranes were developed using ECL Plus detection (GE Healthcare \#RPN-2132) reagents.

Immunoprecipitation of the INSR or IRS1 out of CD19+ CLL cells was done using the antiinsulin receptor beta antibody (29B4) (Santa Cruz Biotech \# SC-09) and the anti-IRS-1 antibody (Santa Cruz Biotech \#SC-559) and protein A/G Plus sepharose (Santa Cruz Biotech \#SC-2003). Briefly, cell lysates from selected CLL cells were cleared through centrifugation and incubated with primary antibodies for $2 \mathrm{~h}$ at $4{ }^{\circ} \mathrm{C}$, followed by incubations 
with protein $\mathrm{A} / \mathrm{G}$ sepharose beads. Beads were collected through centrifugation and washed with $3 \times 1 \mathrm{ml}$ of lysis buffer. Bead-bound protein was liberated by boiling in $1 \times$ SDS-PAGE sample buffer and protein fractioned by SDS-PAGE. Immunoblotting was done as above.

For analysis of insulin-induced signal transduction, negatively selected CD19+ cells from CLL cases with and without INSR expression were incubated for 1.5 hours in RPMI medium without serum and subsequently stimulated with $10 \mathrm{nM}$ insulin or biotinylated goat anti-human IgM F(ab)2 fragments (Southern Biotech \#2022-08) together with avidin for 20 minutes. Cells were washed with ice-cold PBS, spun and pellets snap frozen and stored at $-80^{\circ} \mathrm{C}$. Pellets were lysed and supernatants prepared for immunoblotting with various primary and secondary antibodies at appropriate dilutions followed by ECL as above.

\section{FACS-based measurements of INSR expression in CLL}

CLL samples were thawed in a $37^{\circ} \mathrm{C}$ water bath, added dropwise into prewarmed RPMI medium with $10 \%$ heat-inactivated fetal calf serum (FCS), centrifuged, and washed with ice-cold HBSS (Hyclone cat\#SH30588.02), supplemented with 1\% FCS and $0.05 \%$ sodium azide (Sigma-Aldrich cat\#S2002-100G). Cells were pelleted and then resuspended in cold HBSS, $1 \%$ FCS, $0.05 \%$ azide buffer. Subsequently, $7.5 \times 10^{5}$ cells were blocked for 15 minutes on ice with $10 \mu \mathrm{g}$ unlabeled mouse IgG antibody (Southern Biotech \#0107-01) and $10 \mu \mathrm{g}$ unlabeled goat IgG antibody (Southern Biotech cat\#0109-01). The following isotype controls were used per sample: $0.05 \mu \mathrm{g}$ goat IgG isotype-APC control (Southern Biotech

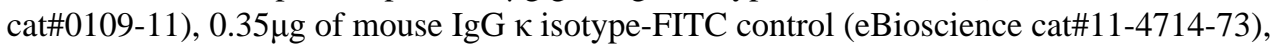
and $0.0875 \mathrm{\kappa g}$ of mouse IgG $\kappa$ isotype-PE (eBioscience cat\#12-4714-73). Duplicate cell aliquots were triple stained with $0.35 \mu \mathrm{g}$ of mouse anti-human CD5-FITC (eBioscience cat\#11-0059-73), $0.0875 \mu \mathrm{g}$ of mouse anti-human CD19-PE (eBioscience cat\#12-0199-42), and $0.05 \mu \mathrm{g}$ of goat anti-human CD220-APC (INSR) (R\&D Systems cat\#FAB1544A). After $1 \mathrm{~h}$ incubation and washings, cells were resuspended in $300 \mu \mathrm{l}$ of $1 \%$ paraformaldehyde solution and analyzed using a BD FACSCalibur flow cytometer and BD CellQuest Pro software. For each sample, isotype controls were run first, and thresholds for positivity were set that allowed $2 \%$ of gated events to be considered positive. Viable lymphocytes (based on light-scatter characteristics) positive for both CD19 and CD5 were then interrogated for INSR expression. INSR expression data in this manuscript are net INSR staining after subtraction of individual background staining.

\section{Measurements of radiation-induced ATM autophosphorylation in CLL}

Measurements of radiation-induced ATM autophosphorylation in CLL were performed as previously reported(34).

\section{SNP 6.0 array-based genomic copy number analysis}

FACS-sorted CD19+ and CD3+ cells were digested overnight in $100 \mathrm{mM}$ Tris $\mathrm{pH}$ 8.0, 50 $\mathrm{mM}$ EDTA, $50 \mathrm{mM} \mathrm{NaCl}, 0.5 \% \mathrm{SDS}$ and $100 \mu \mathrm{g} / \mathrm{ml}$ of Proteinase $\mathrm{K}$ (Invitrogen) at $56^{\circ} \mathrm{C}$. DNA was extracted using phenol-chloroform and precipitated using ammonium acetate, ethanol and glycogen. DNA was prepared for hybridization to SNP 6.0 arrays according to the manufacturers' recommendations. Sample copy number heatmap displays were obtained from CEL files through use of the freely available software dChip adapted to operate in a 64-bit environment(35) as described(36).

\section{Methods used for CLL outcome analysis}

Event times (TTFT, OS) were recorded in months, along with an indicator of whether the event was reached, or the time was censored. Ninety-eight percent of censoring reflects the current status at the date of analysis rather than loss to follow-up. To explore the relationship 
between INSR expression and outcomes, we considered various thresholds that can be used to partition the sample into two groups (high/low INSR expression). The hazard ratio for an outcome (e.g. TTFT) can then be estimated using proportional hazards models. The hazard ratio and the $\mathrm{p}$-value for the null hypothesis that the hazard ratio differs from one (indicating equal hazards in the two groups) are displayed as functions of the threshold.

\section{RESULTS}

\section{Patient Characteristics}

Data from 257 unselected CLL patients (of which $79 \%$ were untreated and $21 \%$ previously treated [median number of prior treatments $=1$ ] at study enrollment) that were consecutively enrolled at the University of Michigan between January 2005 and October 2009 were included in this analysis. Outcome analysis was performed as reported using the date of CLL diagnosis as the reference date(6).

\section{The insulin receptor is expressed in a subset of CLL cases, with preferential expression in CLL with deletion 11q}

Comparative array-based transcriptome analysis between 10 CLL cases with and 9 cases without del11q (all centered on 11q22 and always inclusive of $A T M$ ) resulted in 83 probe sets measuring differential gene expression between the two groups at a false discovery rate of $<0.1$ (33). The majority of the associated genes physically mapped to 11q21-23 and all indicated lower expression in CLL with del11q21-23 than CLL without del11q21-23, providing confidence in our assay conditions (Table 1). Twenty-five probe sets representing 22 differentially expressed genes were not located within del11q21-23; among these, multiple sets identified substantially higher INSR expression ( $\log _{2}$-fold differences of 2.52 , 3 and 3.15) in CLL with del11q21-23 as opposed to the reference cases (Table 1).

To validate the array-based discovery of differential INSR expression in CLL, we measured normalized INSR mRNA expression in mRNA from FACS-sorted CD19+ CLL-derived cells from 247 CLL patients. We grouped CLL by clinically important FISH categories (with all 11q cases clustered as one group, irrespective of other abnormalities) and plotted normalized INSR expression for each case according to genomic CLL subtype. As can be seen in Figure 1A, INSR mRNA expression in CLL covered a wide range and INSR mRNA was expressed at detectable levels in $\sim 50-60 \%$ of all CLL cases. INSR expression was absent in $\sim 40 \%$ of all CLL. Importantly, CLL cases that carried del11q as measured through FISH (using a probe centered on $A T M$ ) had significantly and many fold ( 10-fold) higher INSR mRNA levels than all other FISH-based CLL subgroups (the mRNA data in Figure $1 \mathrm{~A}$ are on a $\sim \log _{2}$-fold scale) and many non-del11q CLL cases did not express the INSR mRNA (with INSR measurements for trisomy 12 patients possibly modestly overestimated through use of the chromosome 12-resident housekeeping gene GAPDH).

To support these INSR mRNA expression findings, we proceeded with INSR immunoblotting on detergent cell lysates from highly enriched CD19+ cells from CLL cases with and without INSR mRNA expression. The INSR protein was readily detected in lysates from CHO cells transfected with an INSR cDNA, as well as in five CLL cases with del11q and detectable INSR mRNA; INSR expression was not detected in CLL cases with absent INSR mRNA (Figure 1B). Next, we determined an approximate threshold for INSR detection by immunoblotting as a function of INSR mRNA level. Using CLL cases spanning the INSR mRNA range of delta Ct INSR-GAPD of 8-11, we detected INSR protein in 11/12 cases; thus INSR protein is readily detectable by immunoblotting in a substantial portion $(\sim 40 \%)$ of all CLL (data not shown). Next we used immunoprecipitation of the INSR from CHO-INSR cells or CLL cells with INSR expression followed by INSR immunoblotting. 
INSR protein was readily detectable in INSR immunoprecipitates but not in parallel precipitates with a control antibody (Figure 1C).

We proceeded to develop a quantitative FACS assay for INSR expression in CD19+/CD5+ cells (see methods). Using this assay we quantitated INSR expression in 257 CLL samples procured at study enrollment. Data are summarized in Figure 2A with CLL cases ordered based on the degree of net INSR expression (range $0.8 \%-76.8 \%$ ). While many cases displayed INSR expression at relatively low levels $(<3 \%,<4 \%$ or $<5 \%$ net INSR expression was found in $30 \%, 60 \%$ and $74 \%$ of cases, respectively), $26 \%(\mathrm{~N}=69)$ of cases expressed the INSR at appreciable levels $(\geq 5 \%)$ and characteristics of these cases are summarized in Supplementary Table 2 (Of the cases with INSR $\geq 5 \%, 69 \%$ [48/69] were ZAP70+ and 31\% [21/69] ZAP70-; furthermore, 73\% [49/67] and 27\% [18/67] were $\operatorname{IgV}_{\mathrm{H}}$ status unmutated and mutated, respectively, with the $\mathrm{IGV}_{\mathrm{H}}$ status of 2 cases not known). A subset of CLL cases expressed very high INSR levels and many of these cases carried del11q (coded in red, see also Figure 3). CLL cases with del17p (coded in blue), in contrast, did not have higher INSR expression than all other CLL. Normal peripheral blood-derived B-cells expressed the INSR at moderate levels (Figure 2B; mean 7.7\%; range 3.2\%-10.1\%), while monocytes were strongly INSR positive (mean $80.2 \%$; range $61.7 \%-90.1 \%$ ).

Next we obtained estimates for the longitudinal stability/instability of INSR expression in individual cases through measurements of INSR expression in paired follow-up samples. Two serial follow-up measurements were available in 89 CLL cases with a range of followup of 15-52 months (median 32 months). One follow-up measurement was available in an additional 54 CLL cases with a range of follow-up of 5-45 months (median 12 months). As can be seen in Supplementary Figure 1, INSR expression was rather stable over time, with few cases demonstrating substantial changes from their baseline values.

In summary, INSR is expressed at the transcript and protein levels in a substantial subset of CLL, prompting investigations into a functional role of the INSR in CLL cells.

\section{The anatomy of mono-allelic 11q deletions in CLL does not provide guidance to differential INSR expression in CLL with del11q}

Attempting to explain why some cases of CLL with 11q deletions did not express the INSR at high levels, we mapped 11q deletions in this cohort using SNP 6.0 ultra-high-resolution arrays and correlated the del11q anatomy with INSR mRNA and protein levels. As can be seen in Figure 3A-B, the position or length of 11q deletions alone is insufficient to explain the observed INSR expression differences. Furthermore, the INSR gene was not amplified.

\section{ATM activity does not correlate with INSR expression}

Given the strong enrichment of CLL cases with del11q amongst the CLL with high INSR expression, it appeared important to test the hypothesis that ATM may be involved in the control of INSR expression. Using a large and unique dataset $(\mathrm{N}=171)$ of radiation-induced ATM autophosphorylation measurements (expressed as normalized p-ATM/ATM and pATM/actin ratios) we were unable to detect evidence for a dominant role of the ATM activity state in the control of INSR expression (Supplementary Figure 2A-D)(34).

The insulin receptor activates canonical insulin signal transduction pathways in CLL cells

In an effort at deriving an initial understanding of INSR-regulated signal transduction in CLL cells, we focused on the AKT-mTOR and Ras-Raf-Erk pathways as known canonical INSR-activated pathways in insulin-responsive cell types (37). 
Highly enriched CD19+ cells from CLL cases with and without INSR expression were stimulated with low-dose insulin at 10nM and cells prepared for immunoblotting with various antibodies (Figure 4A-C). Using an antibody to measure the phosphorylation state at AKT-Ser-473, we detected insulin-induced AKT-Ser-473 stimulation in 11/14 CLL with INSR expression (with more pronounced increases seen in cases with high INSR expression), with the remaining 3/14 cases demonstrating already elevated phospho-AKTSer-473 at baseline. The degree of AKT-Ser-473 phosphorylation was comparable to the phosphorylation induced by B-cell receptor multimerization (Figure 4B). Consistent with insulin-induced mTOR activation, we detected increased phosphorylation of p70-S6 kinase at Ser-389 and S6-ribosomal protein at residues 235/236. Finally, in 7/14 cases, we detected increased insulin-induced Erk1/2 phosphorylation at residues Thr202/Tyr204 while the remaining cases demonstrated elevated baseline Erk1/2 phosphorylation (activation) states, as previously described (38).

Given that IRS-1 is a central INSR signaling node, we investigated insulin-induced IRS-1 phosphorylation on tyrosine in enriched CD19+ CLL cells stimulated with 10nM insulin. IRS-1 was immunoprecipitated from stimulated and unstimulated lysates, protein was fractioned by SDS-PAGE and then transferred to membrane. Tyrosine phosphorylation was detected using the anti-phosphotyrosine-specific antibody 4G10. As can be seen in Figure $4 \mathrm{C}$, insulin stimulation resulted in increased tyrosine phosphorylation on IRS1 in CHOINSR cells as well as primary CLL cells.

\section{Insulin treatment partially abrogates CLL cell apoptosis in short term cultures}

Given the observed insulin-induced activation of the AKT-mTOR pathway in CLL, we proceeded with measurements of CLL apoptosis ex vivo in short term cultures using CLL cells with and without INSR expression and cultured in the presence or absence of 10nM exogenously added insulin. Data were normalized to measured spontaneous apoptosis rates in untreated CLL cells.

As can be seen in Supplementary Figure 3A\&B, insulin consistently abrogated some of the spontaneous apoptosis in CLL cases with INSR expression ( $\mathrm{N}=16$; in red) while most CLL cases without INSR expression ( $\mathrm{N}=16$; in black) proceeded with apoptosis at the same rate as untreated parallel cultured cells. These findings were highly statistically significant $(\mathrm{p}<0.001)$ and provided clear evidence that nanomolar concentrations of insulin can provide pro-survival signals to CLL cells. These data also support a role for the INSR as the primary insulin receptor responsible for the observed insulin effects in CLL.

\section{Expression of the insulin receptor identifies progressive CLL}

We wished to obtain evidence for a role of the INSR in CLL clinical behavior. Initially, we correlated the size of the largest lymph node (LN) or the number of positive $\mathrm{LN}$ stations by physical exam with various INSR thresholds. As summarized in Supplementary Figure 4A$\mathrm{B}$, both measures correlated with elevated INSR expression (a correlation between ALCdoubling time and INSR expression was not found). Next, we analyzed two well-defined clinical endpoints, TTFT (a measure of natural disease progression) and OS, as a function of the degree of INSR expression as measured through FACS. Given that INSR expression was observed in all CLL, albeit at very different absolute levels, we chose to analyze INSR as a continuous variable and calculated hazard ratios for TTFT and OS across a wide range of INSR expression cut-offs. This type of outcome analysis appears more suitable for the observed continuous expression levels of the INSR, as it avoids the use of optimized but nonetheless arbitrary cut-offs for INSR expression and instead provides data for a broad range of INSR expression levels. Using proportional univariate hazard modeling, we found that the hazard ratios for shorter TTFT were correlated to higher INSR protein levels across 
a broad range of absolute INSR levels (Figure 5A-C). For instance, elevated HRs for a short TTFT emerged at INSR levels of $\sim 4 \%$ and remained significantly elevated for all higher cutoffs. Removal of all CLL cases with 11q substantially weakened the power of the analysis but still uncovered effects of the INSR on short TTFT (Figure 5D-F) suggesting that the INSR effect on CLL is independent of 11q but likely contributes to 11q biology given the high INSR expression in this disease subset.

The parallel analysis using OS as the endpoint uncovered univariate associations of high INSR expression on survival in CLL (Figures 5G-L).

\section{INSR expression is associated with rapid initial disease progression in CLL with $<20 \%$ ZAP-70 expression (bivariate analyses)}

ZAP-70 expression identifies a CLL subgroup that progresses to need of first therapy (TTFT) within 3-4 years, and thus ZAP-70 expression constitutes one of the strongest predictors of progressive CLL(5). We therefore performed bivariate analyses to detect effects of INSR expression (at various thresholds) on TTFT and OS in the setting of known ZAP-70 status. As can be seen in Figure 6A-H, INSR expression in CLL with high ZAP-70 expression demonstrated no additional effects on disease progression. However, INSR expression in CLL with ZAP-70 expression of $<20 \%$ was associated with rapid disease progression and shortened OS similar to what was observed in ZAP-70 positive CLL. This finding remained significant for some thresholds, despite substantially lower case numbers, after the exclusion of all 11q cases (data not shown). Conversely, CLL cases with low ZAP-70 and low INSR expression demonstrated substantial disease stability. A parallel bivariate analysis of the effect of INSR expression on CLL with unmutated or mutated $\operatorname{IgV}_{\mathrm{H}}$ genes $\left(\mathrm{IgV}_{\mathrm{H}} \mathrm{UM}\right.$ or $\left.\mathrm{M}\right)$ did not find significant effects for TTFT, but did reveal significant, threshold- dependent effects on OS (Supplementary Figure 5A-H).

\section{Results of multivariate analyses}

Finally, we incorporated INSR expression at various thresholds together with ZAP-70 status and $\operatorname{IgV}_{\mathrm{H}}$ status into multivariate modeling (despite power limitations due to study size). INSR emerged as a risk factor with hazard ratios $>1$ for short OS across multiple thresholds with INSR expression $\geq 10 \%$, demonstrating a trend towards independent significance (INSR HR= 1.91, $\mathrm{p}=0.07 ; \operatorname{IgV}_{\mathrm{H}} \mathrm{HR}=3.13, \mathrm{p}<0.01$; and ZAP-70 HR=2.07, $\mathrm{p}=0.04$ for all cases [N=246] and INSR HR=2.35, $\mathrm{p}=0.07 ; \mathrm{IgV}_{\mathrm{H}} \mathrm{HR}=3.34, \mathrm{p}<0.01$; and $\mathrm{ZAP}-70 \mathrm{HR}=1.91$, $\mathrm{p}=0.1$ for all cases without del11q $[\mathrm{N}=222])$.

\section{DISCUSSION}

In this report, we provide novel data that support a role for the INSR in the pathobiology of CLL. Both the identification of differential INSR expression in CLL and preferential aberrant high-level expression in CLL with del11q resulted from a comparative array-based screen of transcriptome differences comparing CLL cases with del11q versus cases without del11q and subsequent validation of these findings in >250 CLL cases. The INSR expressed on CLL cells subsequent to low-dose insulin stimulation activated pro-survival and progrowth pathways and abrogated CLL apoptosis ex vivo, suggesting that under appropriate conditions the INSR may regulate CLL cells in vivo. Such in vivo effects may be particularly relevant in the LN environment, as elevated INSR levels were associated with increased LN size and numbers(39). Furthermore, INSR expression was associated with CLL disease progression and shortened OS, although definitive data on the independent effects of elevated INSR levels on CLL outcome (or possible effects on CLL subsets like diabetics) requires assessments in larger patient cohorts than available to us for this study(37). A substantially larger study size of 500-1000 patients would allow for a comprehensive multi 
variate analysis of the effects of CLL-FISH categories, specific gene mutations, ZAP70 status, $\operatorname{IgV}_{\mathrm{H}}$ status and INSR status in CLL clinical behavior(5).

Furthermore, we detected rapid initial disease progression as measured through short TTFT and shorter OS in CLL cases with less than 20\% ZAP-70 expression, thus identifying a subgroup of CLL within the ZAP-70 low population that may be driven by the insulin/INSR axis. Such effects may be due to the activation of signal transduction pathways shared by the INSR and the B-cell antigen receptor, most notably the AKT- and pro-proliferative pathways.

The novel finding of high aberrant INSR expression in many cases with del11q is intriguing and suggests a contributory role of the INSR to del11q biology. In contrast, elevated INSR expression was not found in CLL with del17p, providing strong evidence against simple epiphenomenal upregulation of INSR expression in proliferative CLL. Nonetheless, the mechanism of preferential and often very high expression of the INSR in CLL with del11q remains unidentified. The high incidence of INSR expression in CLL with del11q implies a regulatory role of a gene(s), located within the boundaries of 11q deletions, on INSR expression. Such a gene(s) may affect INSR transcription or mRNA stability. Nonetheless, a review of the anatomy of $>20$ CLL cases with 11q deletions based on high-resolution SNParrays, including data of del11q cases with low/absent INSR expression, did not allow for the formulation of a specific hypothesis based on a candidate gene or minimal deleted region. Further, ATM activation (as measured through irradiation-induced ATM phosphorylation) did not correlate with INSR expression; this is based on analysis of $>170$ CLL cases. One potential model that may explain all experimental observations makes use of multiple discrete INSR regulators, one of which is located within 11q deletions. Such a putative 11q-resident INSR regulator may require additional gene or gene product modifications, as mono-allelic deletions appear insufficient to activate INSR expression. Finally, such an 11q-resident INSR regulator may act in concert with non 11q-resident genes (possibly located on chromosome 13, given sporadic high INSR expression observed in this CLL subset) or may be altered or mutated in cases without del11q.

Our findings of INSR expression in CLL add novel information on the role of the INSR in cancer biology and provide the most complete assessment yet of expression and function of this receptor in hematological malignancies $(40,41)$. Given that various compounds based on multiple strategies targeting the IGF1 receptors have entered clinical investigation, we anticipate increased interest in targeting the INSR or insulin levels in cancer as well.

In summary, the novel identification of INSR expression in CLL subtypes and the association of INSR expression with progressive CLL should allow for the development of assays based on INSR expression that could ultimately be useful in CLL clinical management. Further, identification of the insulin/INSR axis as a pathophysiological principle in CLL may be the first step towards targeted intervention (40). Here, control of blood sugar levels and postprandial insulin levels could be envisioned, as could therapeutic interventions based on knowledge of INSR-activated signaling pathways in CLL. Finally, multiple compounds in early stage clinical development targeting IGF1-R also inhibit the INSR at low micromolar concentrations, and thus could be tested for clinical efficacy in CLL with INSR expression (42).

\section{Supplementary Material}

Refer to Web version on PubMed Central for supplementary material. 


\section{Acknowledgments}

Supported by the Translational Research Program of the Leukemia and Lymphoma Society of America (SM). This research is supported (in part) by the National Institutes of Health through the University of Michigan's Cancer Center Support Grant (5 P30 CA46592). We are grateful for services provided by the microarray core of the University of Michigan Comprehensive Cancer Center.

\section{References}

1. Chiorazzi N, Rai KR, Ferrarini M. Chronic lymphocytic leukemia. N Engl J Med. 2005; 352:80415. [PubMed: 15728813]

2. Tam CS, Shanafelt TD, Wierda WG, Abruzzo LV, Van Dyke DL, O'Brien S, et al. De novo deletion 17p13.1 chronic lymphocytic leukemia shows significant clinical heterogeneity: the M. D. Anderson and Mayo Clinic experience. Blood. 2009; 114:957-64. [PubMed: 19414856]

3. Shanafelt TD, Hanson C, Dewald GW, Witzig TE, LaPlant B, Abrahamzon J, et al. Karyotype evolution on fluorescent in situ hybridization analysis is associated with short survival in patients with chronic lymphocytic leukemia and is related to CD49d expression. J Clin Oncol. 2008; 26:e56. [PubMed: 18467710]

4. Saddler C, Ouillette P, Kujawski L, Shangary S, Talpaz M, Kaminski M, et al. Comprehensive biomarker and genomic analysis identifies p53 status as the major determinant of response to MDM2 inhibitors in chronic lymphocytic leukemia. Blood. 2008; 111:1584-93. [PubMed: 17971485]

5. Rassenti LZ, Jain S, Keating MJ, Wierda WG, Grever MR, Byrd JC, et al. Relative value of ZAP-70, CD38, and immunoglobulin mutation status in predicting aggressive disease in chronic lymphocytic leukemia. Blood. 2008; 112:1923-30. [PubMed: 18577710]

6. Kujawski L, Ouillette P, Erba H, Saddler C, Jakubowiak A, Kaminski M, et al. Genomic complexity identifies patients with aggressive chronic lymphocytic leukemia. Blood. 2008; 112:1993-2003. [PubMed: 18436738]

7. Van Den Neste E, Robin V, Francart J, Hagemeijer A, Stul M, Vandenberghe P, et al. Chromosomal translocations independently predict treatment failure, treatment-free survival and overall survival in B-cell chronic lymphocytic leukemia patients treated with cladribine. Leukemia. 2007; 21:171522. [PubMed: 17541398]

8. Zenz T, Krober A, Scherer K, Habe S, Buhler A, Benner A, et al. Monoallelic TP53 inactivation is associated with poor prognosis in chronic lymphocytic leukemia: results from a detailed genetic characterization with long-term follow-up. Blood. 2008; 112:3322-9. [PubMed: 18689542]

9. Grever MR, Lucas DM, Dewald GW, Neuberg DS, Reed JC, Kitada S, et al. Comprehensive assessment of genetic and molecular features predicting outcome in patients with chronic lymphocytic leukemia: results from the US Intergroup Phase III Trial E2997. Journal of Clinical Oncology. 2007; 25:799-804. [PubMed: 17283363]

10. Mayr C, Speicher MR, Kofler DM, Buhmann R, Strehl J, Busch R, et al. Chromosomal translocations are associated with poor prognosis in chronic lymphocytic leukemia. Blood. 2006; 107:742-51. [PubMed: 16179374]

11. Dicker F, Schnittger S, Haferlach T, Kern W, Schoch C. Immunostimulatory oligonucleotideinduced metaphase cytogenetics detect chromosomal aberrations in $80 \%$ of CLL patients: A study of 132 CLL cases with correlation to FISH, IgVH status, and CD38 expression. Blood. 2006; 108:3152-60. [PubMed: 16840733]

12. Rassenti LZ, Huynh L, Toy TL, Chen L, Keating MJ, Gribben JG, et al. ZAP-70 compared with immunoglobulin heavy-chain gene mutation status as a predictor of disease progression in chronic lymphocytic leukemia. N Engl J Med. 2004; 351:893-901. [PubMed: 15329427]

13. Orchard JA, Ibbotson RE, Davis Z, Wiestner A, Rosenwald A, Thomas PW, et al. ZAP-70 expression and prognosis in chronic lymphocytic leukaemia. Lancet. 2004; 363:105-11. [PubMed: 14726163]

14. Wiestner A, Rosenwald A, Barry TS, Wright G, Davis RE, Henrickson SE, et al. ZAP-70 expression identifies a chronic lymphocytic leukemia subtype with unmutated immunoglobulin 
genes, inferior clinical outcome, and distinct gene expression profile. Blood. 2003; 101:4944-51. [PubMed: 12595313]

15. Crespo M, Bosch F, Villamor N, Bellosillo B, Colomer D, Rozman M, et al. ZAP-70 expression as a surrogate for immunoglobulin-variable-region mutations in chronic lymphocytic leukemia. $\mathrm{N}$ Engl J Med. 2003; 348:1764-75. [PubMed: 12724482]

16. Oscier DG, Gardiner AC, Mould SJ, Glide S, Davis ZA, Ibbotson RE, et al. Multivariate analysis of prognostic factors in CLL: clinical stage, IGVH gene mutational status, and loss or mutation of the p53 gene are independent prognostic factors. Blood. 2002; 100:1177-84. [PubMed: 12149195]

17. Lin K, Sherrington PD, Dennis M, Matrai Z, Cawley JC, Pettitt AR. Relationship between p53 dysfunction, $\mathrm{CD} 38$ expression, and $\operatorname{IgV}(\mathrm{H})$ mutation in chronic lymphocytic leukemia. Blood. 2002; 100:1404-9. [PubMed: 12149224]

18. Krober A, Seiler T, Benner A, Bullinger L, Bruckle E, Lichter P, et al. V(H) mutation status, CD38 expression level, genomic aberrations, and survival in chronic lymphocytic leukemia. Blood. 2002; 100:1410-6. [PubMed: 12149225]

19. Chen L, Widhopf G, Huynh L, Rassenti L, Rai KR, Weiss A, et al. Expression of ZAP-70 is associated with increased B-cell receptor signaling in chronic lymphocytic leukemia. Blood. 2002; 100:4609-14. [PubMed: 12393534]

20. Dohner H, Stilgenbauer S, Benner A, Leupolt E, Krober A, Bullinger L, et al. Genomic aberrations and survival in chronic lymphocytic leukemia. N Engl J Med. 2000; 343:1910-6. [PubMed: 11136261]

21. Neilson JR, Auer R, White D, Bienz N, Waters JJ, Whittaker JA, et al. Deletions at 11q identify a subset of patients with typical CLL who show consistent disease progression and reduced survival. Leukemia. 1997; 11:1929-32. [PubMed: 9369428]

22. Damle RN, Wasil T, Fais F, Ghiotto F, Valetto A, Allen SL, et al. Ig V gene mutation status and CD38 expression as novel prognostic indicators in chronic lymphocytic leukemia. Blood. 1999; 94:1840-7. [PubMed: 10477712]

23. Hamblin TJ, Davis Z, Gardiner A, Oscier DG, Stevenson FK. Unmutated Ig V(H) genes are associated with a more aggressive form of chronic lymphocytic leukemia. Blood. 1999; 94:184854. [PubMed: 10477713]

24. Stankovic T, Weber P, Stewart G, Bedenham T, Murray J, Byrd PJ, et al. Inactivation of ataxia telangiectasia mutated gene in B-cell chronic lymphocytic leukaemia. Lancet. 1999; 353:26-9. [PubMed: 10023947]

25. Schaffner C, Stilgenbauer S, Rappold GA, Dohner H, Lichter P. Somatic ATM mutations indicate a pathogenic role of ATM in B-cell chronic lymphocytic leukemia. Blood. 1999; 94:748-53. [PubMed: 10397742]

26. Bullrich F, Rasio D, Kitada S, Starostik P, Kipps T, Keating M, et al. ATM mutations in B-cell chronic lymphocytic leukemia. Cancer Res. 1999; 59:24-7. [PubMed: 9892178]

27. Austen B, Powell JE, Alvi A, Edwards I, Hooper L, Starczynski J, et al. Mutations in the ATM gene lead to impaired overall and treatment-free survival that is independent of IGVH mutation status in patients with B-CLL. Blood. 2005; 106:3175-82. [PubMed: 16014569]

28. Austen B, Skowronska A, Baker C, Powell JE, Gardiner A, Oscier D, et al. Mutation status of the residual ATM allele is an important determinant of the cellular response to chemotherapy and survival in patients with chronic lymphocytic leukemia containing an 11q deletion. J Clin Oncol. 2007; 25:5448-57. [PubMed: 17968022]

29. Herling M, Patel KA, Weit N, Lilienthal N, Hallek M, Keating MJ, et al. High TCL1 levels are a marker of B-cell receptor pathway responsiveness and adverse outcome in chronic lymphocytic leukemia. Blood. 2009; 114:4675-86. [PubMed: 19770358]

30. Cheson BD, Bennett JM, Grever M, Kay N, Keating MJ, O'Brien S, et al. National Cancer Institute-sponsored Working Group guidelines for chronic lymphocytic leukemia: revised guidelines for diagnosis and treatment. Blood. 1996; 87:4990-7. [PubMed: 8652811]

31. Ouillette P, Erba H, Kujawski L, Kaminski M, Shedden K, Malek SN. Integrated genomic profiling of chronic lymphocytic leukemia identifies subtypes of deletion 13q14. Cancer Res. 2008; 68:1012-21. [PubMed: 18281475] 
32. Irizarry RA, Hobbs B, Collin F, Beazer-Barclay YD, Antonellis KJ, Scherf U, et al. Exploration, normalization, and summaries of high density oligonucleotide array probe level data. Biostatistics. 2003; 4:249-64. [PubMed: 12925520]

33. Benjamini, YaHY. Controlling the False Discovery Rate: A Practical and Powerful Approach to Multiple Testing. J R Stat Soc. 1995; 57:289-300.

34. Ouillette P, Fossum S, Parkin B, Ding L, Bockenstedt P, Al-Zoubi A, et al. Aggressive chronic lymphocytic leukemia with elevated genomic complexity is associated with multiple gene defects in the response to DNA double-strand breaks. Clin Cancer Res. 2010; 16:835-47. [PubMed: 20086003]

35. Lin M, Wei LJ, Sellers WR, Lieberfarb M, Wong WH, Li C. dChipSNP: significance curve and clustering of SNP-array-based loss-of-heterozygosity data. Bioinformatics. 2004; 20:1233-40. [PubMed: 14871870]

36. Parkin B, Erba H, Ouillette P, Roulston D, Purkayastha A, Karp J, et al. Acquired genomic copy number aberrations and survival in adult acute myelogenous leukemia. Blood. 2010; 116:4958-67. [PubMed: 20729466]

37. Taniguchi CM, Emanuelli B, Kahn CR. Critical nodes in signalling pathways: insights into insulin action. Nat Rev Mol Cell Biol. 2006; 7:85-96. [PubMed: 16493415]

38. Muzio M, Apollonio B, Scielzo C, Frenquelli M, Vandoni I, Boussiotis V, et al. Constitutive activation of distinct BCR-signaling pathways in a subset of CLL patients: a molecular signature of anergy. Blood. 2008; 112:188-95. [PubMed: 18292287]

39. Dohner H, Stilgenbauer S, James MR, Benner A, Weilguni T, Bentz M, et al. 11q deletions identify a new subset of B-cell chronic lymphocytic leukemia characterized by extensive nodal involvement and inferior prognosis. Blood. 1997; 89:2516-22. [PubMed: 9116297]

40. Pollak M. Insulin and insulin-like growth factor signalling in neoplasia. Nat Rev Cancer. 2008; 8:915-28. [PubMed: 19029956]

41. Wahner Hendrickson AE, Haluska P, Schneider PA, Loegering DA, Peterson KL, Attar R, et al. Expression of insulin receptor isoform A and insulin-like growth factor-1 receptor in human acute myelogenous leukemia: effect of the dual-receptor inhibitor BMS-536924 in vitro. Cancer Res. 2009; 69:7635-43. [PubMed: 19789352]

42. Baserga R. Customizing the targeting of IGF-1 receptor. Future Oncol. 2009; 5:43-50. [PubMed: 19243297] 


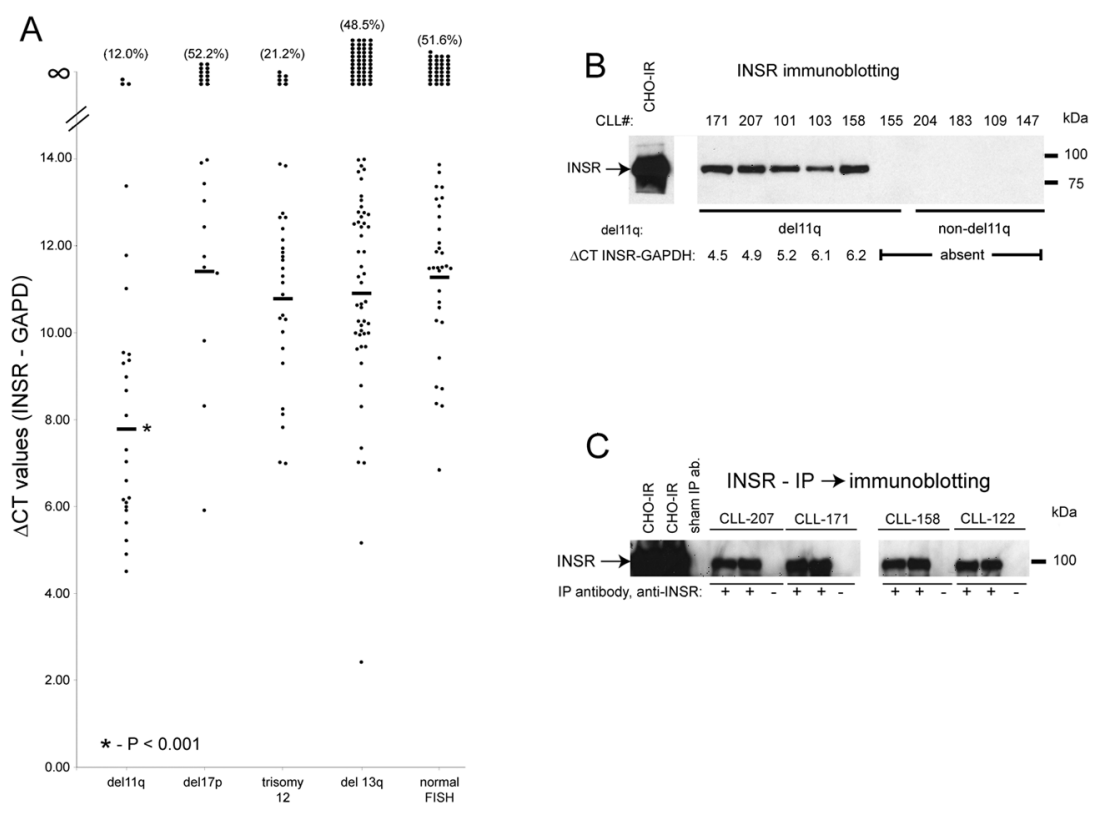

Figure 1. The INSR is expressed in a subset of CLL cases and preferentially in CLL with del11q A: Normalized INSR expression was measured using Q-PCR and the means of duplicate measurements are plotted as individual dots (delta $\mathrm{Ct}$ mean INSR-mean GAPDH;

equivalent to $\log _{2}$-scale). Means of measurements are indicated with horizontal bars. B: INSR immunoblotting results in CHO cells transfected with an INSR cDNA and CLL cases with and without INSR mRNA expression. C: INSR immunoprecipitation followed by INSR immunoblotting results. 

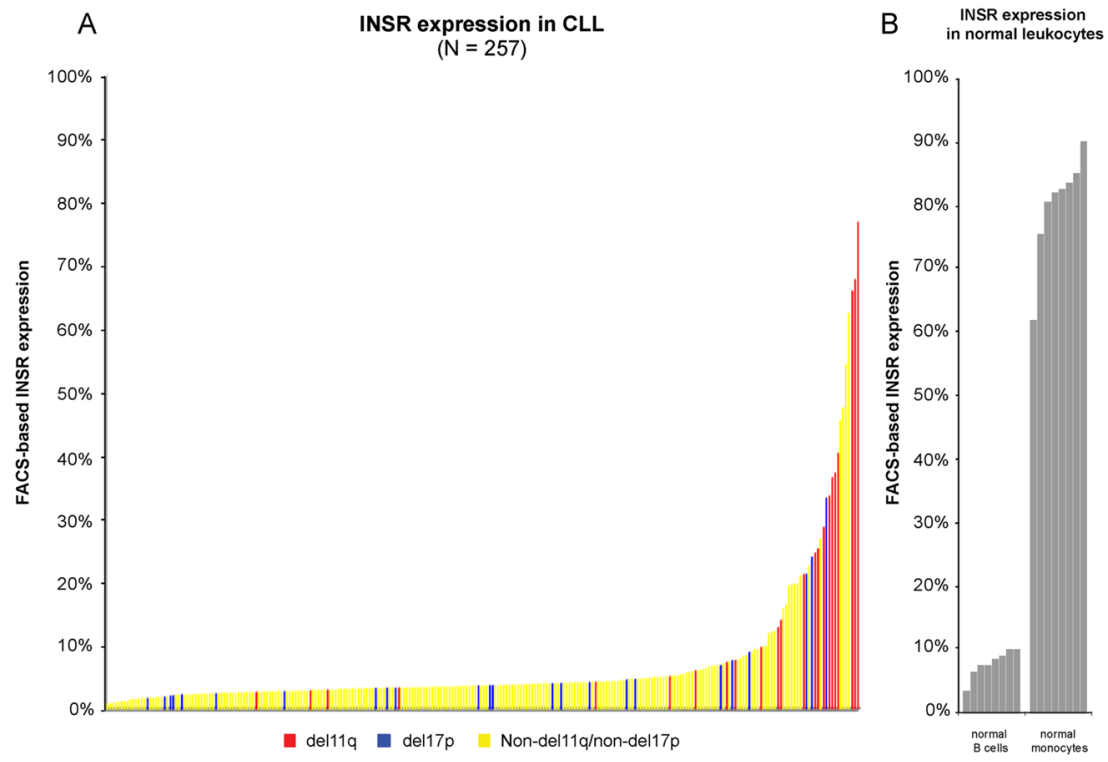

Figure 2. FACS-based INSR expression measurements in a large CLL cohort A: INSR expression was measured in duplicate in gated CD19+/CD5+ cells from PBMCs from 257 patients. Background staining was quantified based on isotype controls (see methods). Displayed are net INSR expression values for individual cases ranked by the magnitude of INSR expression. CLL cases with del11q or del17p present in $\geq 25 \%$ of nuclei are marked in red and blue. B: INSR expression in normal B-cells and monocytes. 


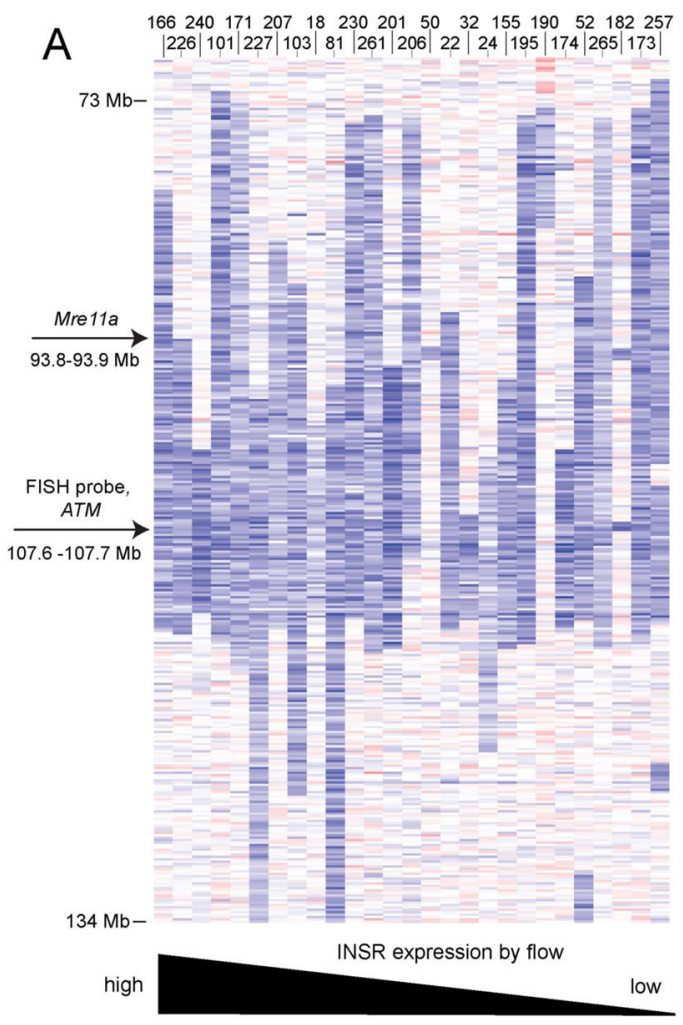

B

$\begin{array}{cccc}\begin{array}{c}\text { CLL } \\ \text { case } \\ \text { number }\end{array} & \begin{array}{c}\% \text { INSR } \\ \text { expression } \\ (\text { FACS) }\end{array} & \begin{array}{c}\Delta \text { CT INSR- } \\ \text { GAPDH } \\ \text { (mRNA) }\end{array} & \begin{array}{c}\text { FISH } \\ \text { (225\% positive) }\end{array} \\ 166 & 76.78 \% & \text { not available } & 11 q, 13 q, 17 p \\ 226 & 67.73 \% & 6.0 & 11 q, 13 q \\ 240 & 65.94 \% & 6.1 & 11 q, 13 q \\ 101 & 40.27 \% & 5.2 & 11 q \\ 171 & 37.17 \% & 4.5 & 11 q, 13 q \\ 227 & 36.47 \% & 7.0 & 11 q, 13 q \\ 207 & 33.56 \% & 4.9 & 11 q, 13 q \\ 103 & 28.60 \% & 6.1 & 13 q, 11 q \\ 18 & 25.19 \% & 5.9 & 11 q \\ 81 & 24.55 \% & 5.6 & 11 q, 13 q \\ 230 & 21.15 \% & 8.1 & 11 q, \text { monosomy } 6 \\ 261 & 16.33 \% & 8.4 & 11 q, 13 q \\ 201 & 13.95 \% & 9.5 & 11 q, \text { trisomy } 12 \\ 206 & 12.79 \% & 9.5 & 11 q, \text { trisomy12 } \\ 50 & 12.22 \% & 8.4 & \text { normal } \\ 22 & 7.61 \% & 7.3 & 11 q, \text { trisomy } 12,13 q \\ 32 & 7.32 \% & 9.4 & 11 q, \text { trisomy } 12 \\ 24 & 6.01 \% & 6.6 & 6 q, 11 q \\ 155 & 5.11 \% & \text { absent } & 11 q \\ 195 & 4.19 \% & 11.8 & 11 q \\ 190 & 3.98 \% & 11.5 & 17 p \\ 174 & 3.51 \% & \text { not available } & \text { trisomy 12, 13q } \\ 52 & 3.30 \% & 9.3 & 6 q, 11 q \\ 265 & 3.14 \% & \text { absent } & 11 q, 13 q \\ 182 & 2.85 \% & \text { absent } & 13 q, 11 q \\ 173 & 2.62 \% & 13.4 & 11 q, 13 q \\ 257 & 2.03 \% & \text { absent } & 17 p, 13 q, 11 q \\ & & & \end{array}$

Figure 3. The anatomy of 11q deletions in CLL does not explain differences in INSR expression A: Heatmap display of copy number estimates for parts of chromosome 11 (blue: copy loss; red: copy gain) based on SNP 6.0 array profiling. The location of the ATM-centric FISH probe used clinically is indicated. Cases are ordered by degree of INSR expression. B:

Summary of Q-PCR-based normalized INSR mRNA levels ( $\triangle \mathrm{Ct}$ INSR-GAPDH values) and FACS-based INSR protein expression levels for the CLL cases with 11q deletions marked in panel A. 
A Immunoblotting: INSR, pAkt, Akt in primary CLL

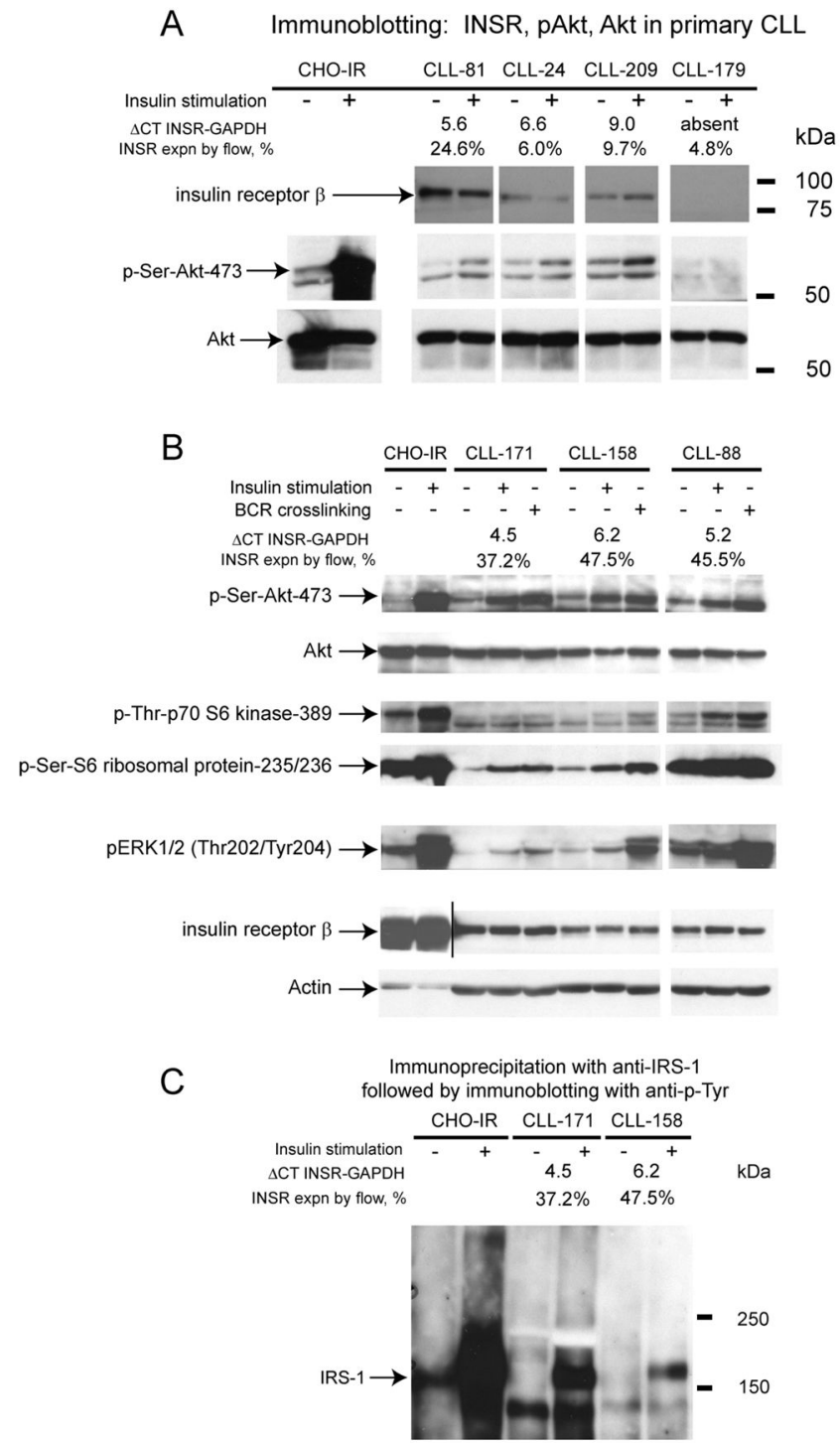

Figure 4. The INSR activates canonical INSR signal transduction pathways in CLL

Panel A-B: CD19+ cells from selected CLL cases were cultured and left untreated or stimulated with $10 \mathrm{nM}$ insulin. Detergent lysates were prepared, protein was fractioned by SDS-PAGE, transferred to membrane and subsequently prepared for immunoblotting with various antibodies as indicated. For data presented in panel B, aliquots of cells were also stimulated in parallel with a combination of biotinylated anti-IgM F(ab) $)_{2}$ fragments together with avidin. C: Immunoprecipitation of IRS1 out of CHO-IR or CD19+ CLL-derived cells left untreated or treated with $10 \mathrm{nM}$ insulin followed by immunoblotting with antiphosphotyrosine antibodies. The approximate position of pre-stained molecular weight markers is indicated. 

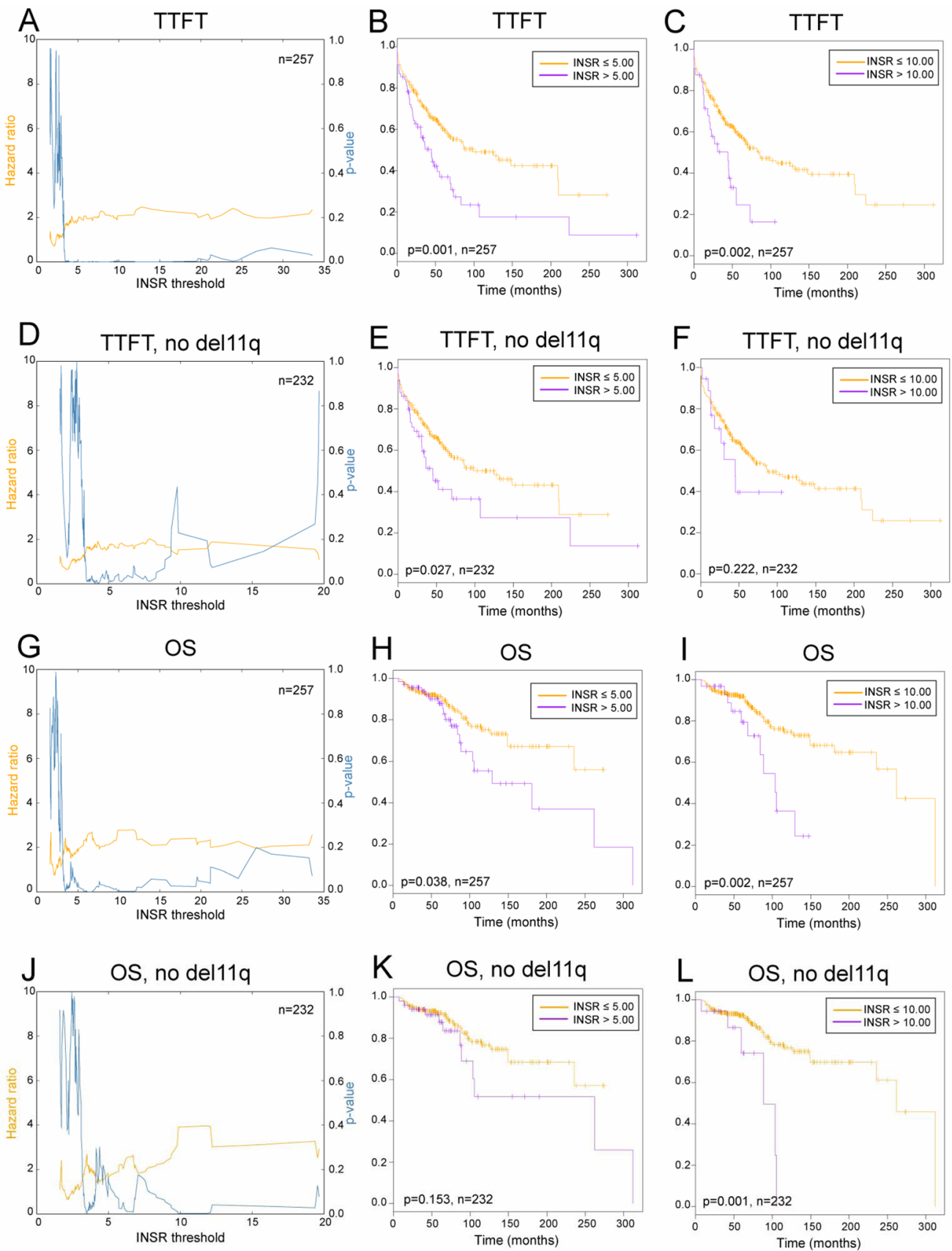

Figure 5. Higher INSR expression is associated with elevated hazard ratios for CLL disease progression or short OS over a broad range of actual INSR expression values Displayed are hazard ratios (yellow) and corresponding p-values (blue) as a function of various INSR protein thresholds measured through FACS. A-C: TTFT and various INSR thresholds (all cases). D-F: TTFT and various INSR thresholds (all cases minus 11q cases). G-I: OS and various INSR thresholds (all cases). J-L: OS and various INSR thresholds (all cases minus $11 \mathrm{q}$ cases). 

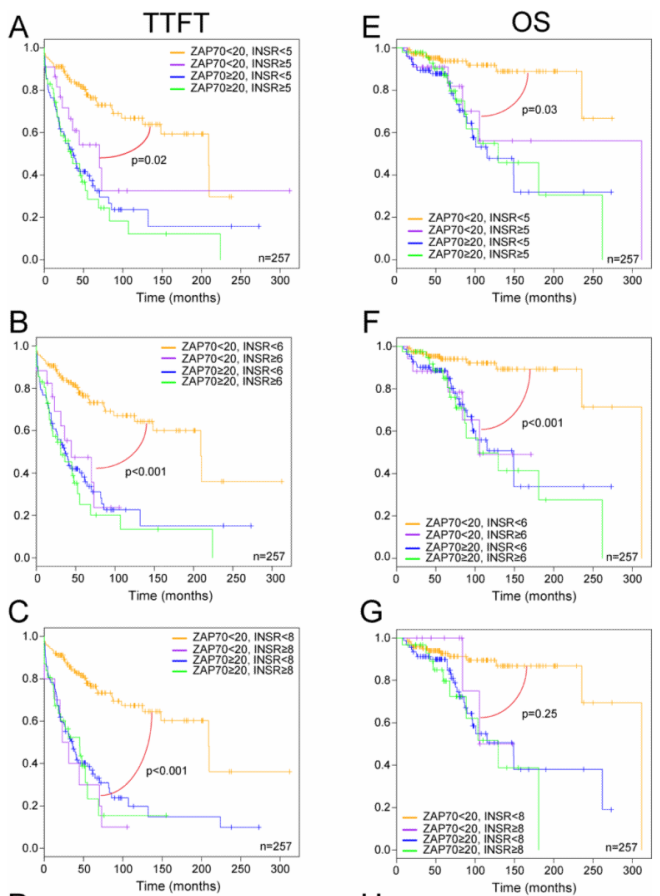

G
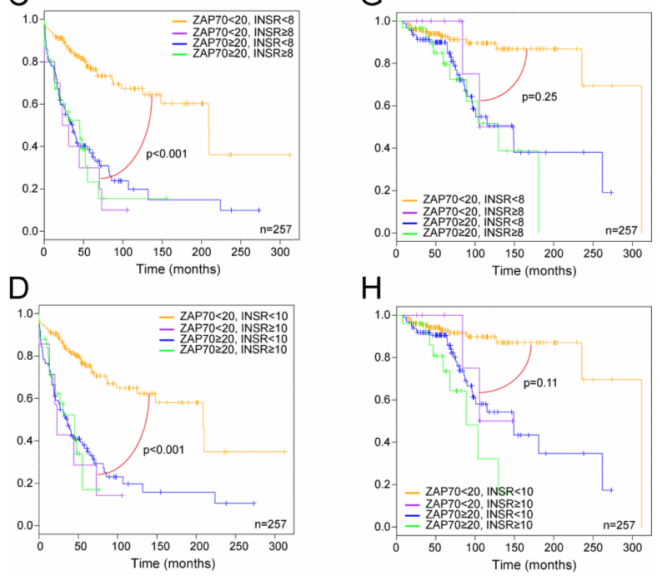

Figure 6. INSR expression is associated with rapid disease progression and shortened OS in CLL with low ZAP-70 expression (bivariate analysis, KM-plots)

Displayed are KM-plots as a function of various INSR protein thresholds as measured through FACS. A-H: TTFT or OS and various INSR thresholds in the setting of ZAP-70 expression of $\geq 20 \%$ or $<20 \%$. 
Table 1

List of differentially expressed genes between CLL cases with and without deletion 11q, ranked by significance levels at a FDR of $<0.1$.

\begin{tabular}{|c|c|c|c|c|}
\hline Probe ID & Symbol & Cytoband & Log2-fold change & FDR \\
\hline 203647_s_at & FDX1 & $11 \mathrm{q} 22$ & -1.06 & $3 \mathrm{E}-05$ \\
\hline 219374_s_at & ALG9 & $11 \mathrm{q} 23$ & -0.96 & $8 \mathrm{E}-05$ \\
\hline 204977_at & DDX10 & $11 \mathrm{q} 22$ & -0.95 & 9E-05 \\
\hline 229989_at & LOC91893 & $11 \mathrm{q} 23$ & -1.23 & $1 \mathrm{E}-04$ \\
\hline 237040_at & CWF19L2 & $11 \mathrm{q} 22$ & -0.91 & $1 \mathrm{E}-04$ \\
\hline 202170_s_at & AASDHPPT & $11 \mathrm{q} 22$ & -1.10 & $2 \mathrm{E}-04$ \\
\hline 203532_x_at & CUL5 & $11 \mathrm{q} 22$ & -1.27 & $5 \mathrm{E}-04$ \\
\hline 205412_at & ACAT1 & $11 q 22$ & -0.92 & $1 \mathrm{E}-03$ \\
\hline 235045_at & RBM7 & $11 \mathrm{q} 23$ & -0.94 & $1 \mathrm{E}-03$ \\
\hline 211584_s_at & NPAT & $11 \mathrm{q} 22$ & -1.02 & $1 \mathrm{E}-03$ \\
\hline 202883_s_at & PPP2R1B & $11 \mathrm{q} 23$ & -0.72 & $2 \mathrm{E}-03$ \\
\hline 232449_at & $\mathrm{BCDO} 2$ & $11 \mathrm{q} 22$ & -0.95 & $2 \mathrm{E}-03$ \\
\hline 209798_at & NPAT & $11 \mathrm{q} 22$ & -0.67 & $2 \mathrm{E}-03$ \\
\hline 240621_at & ATM & $11 \mathrm{q} 22$ & -1.05 & $2 \mathrm{E}-03$ \\
\hline 218400_at & OAS3 & $12 q 24$ & 2.04 & $2 \mathrm{E}-03$ \\
\hline 1566514_at & CWF19L2 & $11 \mathrm{q} 22$ & -0.94 & $3 \mathrm{E}-03$ \\
\hline 235610_at & ALKBH8 & $11 \mathrm{q} 22$ & -0.77 & $4 \mathrm{E}-03$ \\
\hline 209694_at & PTS & $11 \mathrm{q} 22$ & -1.03 & $4 \mathrm{E}-03$ \\
\hline 227432_s_at & INSR & $19 \mathrm{p} 13$ & 3.00 & $4 E-03$ \\
\hline 1558589_at & C21orf15 & $21 \mathrm{q} 11$ & -3.31 & $4 \mathrm{E}-03$ \\
\hline 203533_s_at & CUL5 & $11 \mathrm{q} 22$ & -0.78 & $4 \mathrm{E}-03$ \\
\hline 226450_at & INSR & $19 \mathrm{p} 13$ & 2.52 & $4 E-03$ \\
\hline 213792_s_at & INSR & $19 \mathrm{p} 13$ & 3.15 & $4 E-03$ \\
\hline 223151_at & DCUN1D5 & $11 \mathrm{q} 22$ & -0.67 & $5 \mathrm{E}-03$ \\
\hline 1553750_a_at & FAM76B & $11 \mathrm{q} 21$ & -0.93 & $5 \mathrm{E}-03$ \\
\hline 228777_at & KBTBD3 & $11 \mathrm{q} 22$ & -0.69 & $8 \mathrm{E}-03$ \\
\hline 230393_at & CUL5 & $11 \mathrm{q} 22$ & -0.84 & $8 \mathrm{E}-03$ \\
\hline 212672_at & ATM & $11 \mathrm{q} 22$ & -0.63 & $8 \mathrm{E}-03$ \\
\hline 231472_at & FBXO15 & $18 \mathrm{q} 22$ & 1.05 & $10 \mathrm{E}-03$ \\
\hline 202884_s_at & PPP2R1B & $11 \mathrm{q} 23$ & -0.62 & $1 \mathrm{E}-02$ \\
\hline 1559028_at & LOC284233 & $18 \mathrm{p} 11$ & -2.64 & $1 \mathrm{E}-02$ \\
\hline 211150_s_at & DLAT & $11 \mathrm{q} 23$ & -0.81 & $2 \mathrm{E}-02$ \\
\hline 218314_s_at & C11orf57 & $11 \mathrm{q} 23$ & -0.55 & $2 \mathrm{E}-02$ \\
\hline 235713_at & ALKBH8 & $11 \mathrm{q} 22$ & -0.68 & $2 \mathrm{E}-02$ \\
\hline 214463_x_at & HIST1H4K & $6 \mathrm{p} 22$ & -0.71 & $2 \mathrm{E}-02$ \\
\hline 223430_at & SNF1LK2 & $11 \mathrm{q} 23$ & -0.72 & $2 \mathrm{E}-02$ \\
\hline
\end{tabular}




\begin{tabular}{|c|c|c|c|c|}
\hline Probe ID & Symbol & Cytoband & Log2-fold change & FDR \\
\hline 232048_at & FAM76B & $11 \mathrm{q} 21$ & -0.82 & $2 \mathrm{E}-02$ \\
\hline 218194_at & REXO2 & $11 \mathrm{q} 23$ & -0.68 & $2 \mathrm{E}-02$ \\
\hline 231837_at & USP28 & $11 \mathrm{q} 23$ & -0.75 & $2 \mathrm{E}-02$ \\
\hline 231538_at & C11orf1 & $11 \mathrm{q} 23$ & -1.00 & $3 \mathrm{E}-02$ \\
\hline 221438_s_at & TEX12 & $11 \mathrm{q} 23$ & -0.65 & $3 \mathrm{E}-02$ \\
\hline 1554947_at & ACAT1 & $11 \mathrm{q} 22$ & -0.62 & $3 \mathrm{E}-02$ \\
\hline 204969_s_at & RDX & $11 \mathrm{q} 23$ & -0.94 & $3 \mathrm{E}-02$ \\
\hline 218379_at & RBM7 & $11 \mathrm{q} 23$ & -0.90 & $3 \mathrm{E}-02$ \\
\hline 210858_x_at & ATM & $11 \mathrm{q} 22$ & -0.88 & $3 \mathrm{E}-02$ \\
\hline 230724_s_at & C11orf57 & $11 \mathrm{q} 23$ & -0.76 & $3 \mathrm{E}-02$ \\
\hline 202026_at & SDHD & $11 \mathrm{q} 23$ & -0.67 & $3 \mathrm{E}-02$ \\
\hline 209737_at & MAGI2 & $7 \mathrm{q} 21$ & 1.29 & $3 \mathrm{E}-02$ \\
\hline 208442_s_at & ATM & $11 \mathrm{q} 22$ & -0.97 & $3 \mathrm{E}-02$ \\
\hline 231530_s_at & C11orf1 & $11 \mathrm{q} 23$ & -0.95 & $3 \mathrm{E}-02$ \\
\hline 222785_x_at & C11orf1 & $11 \mathrm{q} 23$ & -0.95 & $4 \mathrm{E}-02$ \\
\hline 1559239_s_at & ACAT1 & $11 \mathrm{q} 22$ & -0.75 & $4 \mathrm{E}-02$ \\
\hline 202912_at & ADM & $11 \mathrm{p} 15$ & 2.23 & $4 \mathrm{E}-02$ \\
\hline 1552825_at & ZNF396 & $18 \mathrm{q} 12$ & 0.66 & $4 \mathrm{E}-02$ \\
\hline 203491_s_at & CEP57 & $11 \mathrm{q} 21$ & -0.84 & $4 \mathrm{E}-02$ \\
\hline 228817_at & ALG9 & $11 \mathrm{q} 23$ & -0.66 & $5 \mathrm{E}-02$ \\
\hline 203531_at & CUL5 & $11 \mathrm{q} 22$ & -0.54 & $5 \mathrm{E}-02$ \\
\hline 1552422_at & C10orf25 & $10 \mathrm{q} 11$ & 1.00 & $5 \mathrm{E}-02$ \\
\hline 208580_x_at & HIST1H4J & $6 \mathrm{p} 22$ & -0.68 & $5 \mathrm{E}-02$ \\
\hline 218412_s_at & GTF2IRD1 & $7 \mathrm{q} 11$ & 2.15 & $5 \mathrm{E}-02$ \\
\hline 205944_s_at & CLTCL1 & $22 q 11$ & 1.60 & 7E-02 \\
\hline 213149_at & DLAT & $11 \mathrm{q} 23$ & -0.76 & $7 \mathrm{E}-02$ \\
\hline 202351_at & ITGAV & $2 q 31$ & 2.82 & $7 \mathrm{E}-02$ \\
\hline 1569431_at & PAFAH1B2 & $11 \mathrm{q} 23$ & -0.55 & $7 \mathrm{E}-02$ \\
\hline 209310_s_at & CASP4 & $11 \mathrm{q} 22$ & -0.66 & $7 \mathrm{E}-02$ \\
\hline 222588_s_at & C11orf57 & $11 \mathrm{q} 23$ & -0.69 & $7 \mathrm{E}-02$ \\
\hline 1563906_at & SOBP & $6 \mathrm{q} 21$ & 1.18 & $7 \mathrm{E}-02$ \\
\hline 205352_at & SERPINI1 & $3 q 26$ & 0.84 & 7E-02 \\
\hline 217388_s_at & KYNU & $2 q 22$ & -0.62 & $7 \mathrm{E}-02$ \\
\hline 225270_at & NEO1 & $15 \mathrm{q} 22$ & 1.46 & 7E-02 \\
\hline 233613_x_at & REXO2 & $11 \mathrm{q} 23$ & -0.71 & 7E-02 \\
\hline 1555803_a_at & C11orf57 & $11 \mathrm{q} 23$ & -0.70 & $7 \mathrm{E}-02$ \\
\hline 1566515_at & CWF19L2 & $11 \mathrm{q} 22$ & -0.68 & $7 \mathrm{E}-02$ \\
\hline 1552988_at & C11orf65 & $11 \mathrm{q} 22$ & -0.82 & $7 \mathrm{E}-02$ \\
\hline 234698_at & N6AMT1 & $21 \mathrm{q} 21$ & 0.99 & 7E-02 \\
\hline
\end{tabular}




\begin{tabular}{|c|c|c|c|c|}
\hline Probe ID & Symbol & Cytoband & Log2-fold change & FDR \\
\hline 229034_at & SOBP & $6 \mathrm{q} 21$ & 1.20 & $8 \mathrm{E}-02$ \\
\hline 234978_at & SLC36A4 & $11 \mathrm{q} 21$ & -0.69 & $8 \mathrm{E}-02$ \\
\hline 1560029_a_at & C11orf57 & $11 \mathrm{q} 23$ & -0.71 & $8 \mathrm{E}-02$ \\
\hline 232248_at & SIDT2 & $11 \mathrm{q} 23$ & -0.63 & $8 \mathrm{E}-02$ \\
\hline 219429_at & FA2H & $16 \mathrm{q} 23$ & -2.16 & 9E-02 \\
\hline 1570119_at & PDS5B & $13 \mathrm{q} 12$ & -0.68 & 9E-02 \\
\hline 225646_at & CTSC & $11 \mathrm{q} 14$ & -0.66 & 9E-02 \\
\hline 202076_at & BIRC2 & $11 \mathrm{q} 22$ & -0.53 & $10 \mathrm{E}-02$ \\
\hline
\end{tabular}

